\title{
A natureza da ciência no ensino de física: entre recortes e sugestões
}

\section{The nature of science in physics teaching: between clippings and suggestions}

\author{
L. H. M. ArthurY*1 \\ ${ }^{1}$ Instituto Federal de Santa Catarina.
}

\begin{abstract}
Resumo
Neste trabalho, fazemos um apanhado dos principais argumentos para o uso de elementos da natureza da ciência no ensino de física, trazendo alguns exemplos de trabalhos com essa preocupação e sugestões correlatas. Pretendemos, assim, contribuir com a instrumentalização do professor de física para que possa otimizar suas práticas em sala de aula em prol de um discurso mais consonante com as pesquisas sobre a natureza da ciência e seu ensino.
\end{abstract}

Palavras-chave: Natureza da ciência. Ensino de física. História e filosofia da ciência no ensino.

*luizarthury@gmail.com 


\begin{abstract}
In this work, we provide an overview of the main arguments for the use of elements of the nature of science in the teaching of physics, bringing some examples of works with this concern and related suggestions. Thus, we intend to contribute with the instrumentalization of the physics teacher so that he can optimize his practices in the classroom in favor of a discourse more in line with research on the nature of science and its teaching.
\end{abstract}

Keywords: Nature of science. Physics teaching. History and philosophy of Science in teaching.

\title{
I. INTRODUÇÃO
}

A ciência atingiu seu status de detentora da verdade por causa de seu método objetivo de investigação. O Método Científico consiste em um repetido ciclo de observação neutra e objetiva, experimentação e prova, que nos garante atingirmos a verdade por meio de nosso raciocínio lógico. As induções obtidas por meio de experimentos têm nos dado um retrato fiel da realidade, e as descobertas científicas, acumuladas por décadas e mesmo séculos de pesquisa, nos dão hoje o conhecimento definitivo presente nos livros de biologia, física e química. São estes conteúdos que devemos passar aos estudantes, para que compreendam o funcionamento da ciência e como as conclusões cientificamente provadas nos dão a certeza de termos entendido os fenômenos naturais. Fora do conhecimento provado da ciência, só resta a mera opinião.

É, no mínimo, curioso que o entendimento da atividade científica ilustrado no parágrafo anterior encontre tanta aceitação, até mesmo entre professores de ciências (FERNÁNDEZ et al., 2002). Essa visão cientificista ingênua é frequentemente propalada na sociedade e, diferentemente do que se poderia esperar, as disciplinas de ciências, na escola, não têm contribuído para mudar essa situação. Por manter sua atenção na transmissão dos resultados da ciência, a prática ordinária do ensino de ciências centrada na exposição de conteúdos e resolução de exercícios voltados a tão somente mobilizar esses mesmos conteúdos não permite que o estudante adquira uma compreensão adequada da atividade científica. Pensamos que isso é bastante previsível, naturalmente. Thomas Kuhn já tinha sugerido que "um conceito da ciência extraído das suas páginas não tem maiores probabilidades de a representar corretamente do que uma imagem duma cultura nacional extraída de um folheto turístico"(1970, p. 19).

O conjunto de saberes relativos à atividade científica como um empreendimento humano, com todas as suas características históricas e filosóficas, incluindo seus fatores culturais, passou a ser conhecido como "natureza da ciência"(LEDERMAN, 2007), um termo que de modo algum é consensual e rigorosamente definido. De modo geral, usamos esse termo para nos referirmos às discussões sobre o que é (e o que não é) ciência, com preocupações com o contexto de produção das teorias científicas para além de seus resultados. No contexto do ensino, isso ultrapassa significativamente os propósitos tradicionais de se trabalhar tão 
somente com os conceitos tidos como "fechados", necessários a uma adequada compreensão dos fenômenos da natureza, da physis, mas ao mesmo tempo totalmente insuficientes para se compreender a atividade científica, como lembrou Kuhn acima.

Existem incontáveis trabalhos que discutem a natureza da ciência, aportados em diferentes referenciais epistemológicos. Não é nosso interesse fazermos essa discussão aqui, sendo nossa intenção apresentar algumas discussões acadêmicas voltadas ao ensino de física com um olhar dirigido a questões sobre a natureza da ciência nesse contexto.

\section{Contextualizando}

Um dos pioneiros a implementar propostas de ensino mais compromissadas com a natureza da ciência foi Gerald Holton, organizador de um projeto que viria ser referência para outros na área. O Projeto Harvard de Ensino de Física, na década de 1970, possuía uma abordagem que transcendia o currículo tradicional de física, abordando suas relações com outras áreas do saber, que melhor identificavam o conhecimento científico na sociedade. Holton é contundente ao sugerir que "o público que não tem conhecimento científico suficiente, mesmo que de forma elementar, seja através da educação escolar, seja através de leituras, não é propriamente são. [...] A educação científica não é apenas uma questão de democracia, mas de sanidade social"(HOLTON, citado em OLIVEIRA; FREIRE Jr., 2006, p. 322). E, justamente pela importância do ensino da ciência, Holton defende que abordagens conectivas, ou seja, contextualizadas e preocupadas com questões históricas e relações com outras áreas do conhecimento, podem atrair um número maior de alunos para esta disciplina, que costuma ter uma baixa procura pelos estudantes em geral (HOLTON, 1979). "Verificamos que uma abordagem mais humanista da ciência pode ampliar o grupo de estudantes em potencial"(HOLTON, 1979, p. 252). De fato, o Projeto Harvard, e suas extensões aos níveis mais básicos de educação, chegou a atingir 15\% dos alunos de todo os Estados Unidos, elevando as médias dos estudantes em ciências (MATTHEWS, 1995).

Naturalmente o contexto onde este projeto foi aplicado era distinto da educação brasileira, mas seus resultados positivos sugeriam que propostas semelhantes podiam ser de valia em outras instituições e países. Foi o que aconteceu no Brasil, quando o projeto Harvard influenciou parte dos projetos nacionais na década de 1970, como o PEF (Projeto de Ensino de Física), e, ainda mais diretamente, a partir da década de 1980, quando da tradução do Projeto Harvard para nosso idioma, o que resultou em um aumento do interesse pela pesquisa na área, pelos pesquisadores em ensino de física (PENA, 2012).

Holton sugeria, no projeto Harvard, um ensino que servisse ao propósito de "desenvolver uma sequência de ideias organicamente relacionadas, cujo estudo leva o aluno a um ponto de vista mais elevado, uma visão mais geral da natureza funcional, do estilo de vida do cientista e do poder da mente humana"(HOLTON, 1979, p. 255). Vários autores compactuam com esta sugestão em suas atividades profissionais (MARTINS, 1990; MATTHEWS, 1995; VILLANI, 2001; ZYLBERSZTAJN, 1988, SOLBES; TRAVER, 2001; SILVEIRA; PEDUZZI, 2006; PEDUZZI et al., 1992; GIL-PÉREZ, 2001; FREIRE Jr., 2002; MOREIRA et al., 2007; GAGLIARDI, 1988; TEIXEIRA et al., 2001). Os profissionais que defendem a utilização da história e a epistemologia no ensino buscam maneiras mais efetivas de se obter uma educação científica abrangente em diversos contextos: "ético, social, histórico, filosófico e 
tecnológico; o que não deixa de ser um redimensionamento do velho argumento de que o ensino de ciências deveria ser, simultaneamente, em e sobre ciências"(MATTHEWS, 1995, p. 166).

O "velho argumento"na citação acima se refere a propostas do final do século XIX, quando o físico e filósofo Ernst Mach já defendia a compreensão do desenvolvimento histórico dos conceitos para que as teorias fossem melhor compreendidas.

A investigação histórica do desenvolvimento da ciência é extremamente necessária a fim de que os princípios que guarda como tesouros não se tornem um sistema de preceitos apenas parcialmente compreendidos ou, o que é pior, um sistema de pré-conceitos. A investigação histórica não somente promove a compreensão daquilo que existe agora, mas também nos apresenta novas possibilidades (MACH, citado em MATTHEWS, 1995, p. 169).

Algumas críticas a este tipo de ensino podem ser encontradas em autores como Martin Klein e Thomas Kuhn (MATTHEWS, 1995), Sánchez Ron (1988) e Acevedo et al. (2005). Esse último coloca que o ensino da natureza da ciência deve estar a serviço da educação em ciências, mas alerta para o uso abusivo de sua proposta, sugerindo que os debates em torno da epistemologia não interessam ao aluno, e que o ensino da natureza da ciência teria um grande problema, diga-se, o de se propor qual visão de ciência será ensinada. Naturalmente existe um pluralismo de visões epistemológicas, de diferentes pensadores em diferentes épocas, o que certamente exige um conhecimento adequado e um discernimento por parte do professor, para que possa escolher quais elementos serão usados no ensino, sem que se passe uma imagem inadequada da atividade científica (o que de modo algum é algo trivial).

Para Klein, os recortes históricos realizados com fins educativos implicam em uma história de má qualidade e que, portanto, é preferível não usá-la (MATTHEWS, 1995). Embora aceitemos que a história precise ser simplificada para que seja utilizada com o propósito de se trabalhar com a natureza da ciência em sala de aula, não pensamos que essa história seja necessariamente de má qualidade, do mesmo modo como as simplificações habitualmente feitas na física escolar não a fazem uma física de má qualidade. O contraargumento de Matthews é contundente:

Na pedagogia, como na maioria das coisas, muitas vezes a matéria tem que ser simplificada. E isto é tão verdadeiro para a história da ciência quanto o é para: a economia, ou para a própria ciência. Porém o fato de que a história da ciência seja simplificada não se torna um argumento decisivo contra ela. A tarefa da pedagogia é, então, a de produzir uma história simplificada que lance uma luz sobre a matéria, mas que não seja uma mera caricatura do processo histórico (MATTHEWS, 1995, p. 177).

Os apontamentos feitos por Thomas Kuhn se relacionam com a própria formação do cientista, onde não haveria lugar para críticas do que está sendo ensinado. Para Kuhn, a educação do cientista "semeia o que a comunidade científica, com dificuldade, alcançou até aí: 
uma adesão profunda a uma maneira particular de ver o mundo e praticar ciência"(KUHN, 1979 , p. 55). A iniciação científica do aluno em moldes rígidos e não discutíveis seria necessária, segundo Kuhn, uma vez que é ela que garante ao aluno um foco de estudos que define o sucesso da ciência moderna em um nível nunca antes atingido, quando este tipo de educação não existia (KUHN, 1970). Nessa linha de raciocínio, uma educação científica que trouxesse ao aluno discussões críticas sobre a natureza da ciência poderia solapar suas convicções, desestimulando-o em sua formação. Embora a preocupação pareça legítima, "não há evidências de que tais abordagens diminuam o entendimento científico; elas podem abalar uma certa convicção pseudocientífica, o que não é de todo mal"(MATTHEWS, 1995, p. 178).

Uma visão inadequada da atividade científica que é frequentemente propalada por professores se refere às pseudo-histórias, o que, a princípio, constitui-se em mais uma crítica em relação às formas contextuais de ensino de ciências. A pseudo-história, como a pseudociência, usa fatos de forma seletiva, ocultando (por desconhecimento ou por máintenção deliberada) outros que melhor o contextualizam, podendo formar uma imagem de ciência anedótica, que não encontra embasamento em uma análise compromissada da atividade científica.

Os cientistas idealizados de mitos romanceados provê modelos não realistas para o que os cidadãos podem esperar dos cientistas em nossa sociedade. Eles distorcem a natureza do conhecimento científico ocultando seus limites e simplificando em demasia a natureza da evidência e interpretação (ALLCHIN, 2004, p. 192).

Como Allchin (2004, p. 192) alerta, como poderemos esperar que estudantes se posicionem criticamente em relação a assuntos científicos se tudo o que eles possuírem forem uma imagem romanceada e irreal da atividade científica? Deste modo, o próprio Allchin estabelece críticas às reconstruções históricas realizadas em qualquer tentativa didática, uma vez que essas invariavelmente incorrerão em modos epistemologicamente partidários de contar uma história. Contudo, há de se começar sempre por algum lugar, e ao se transformar obstáculos contornáveis em intransponíveis não se irá contribuir para gerenciar os desafios que a educação científica enfrenta. Como Silva e Laburú sugerem,

não é questionável aceitar que uma investigação histórica seja legitimada somente quando se basear no caráter completo dos dados? Obviamente que é ilusão pensar em tal "completude", já que ela é absolutamente inalcançável. Tendo considerado que o passado constitui uma fonte inesgotável de informação e que ao historiador cabe, ainda que de forma particular, organizar e selecionar a informação para criar um fio condutor pelo qual os meros fatos poderão adquirir um sentido, não é surpreendente, pelo menos em ensino de ciências, arrefecer essa preocupação (2010, p. 79).

Quando se pretende ensinar física, e não especificamente história da ciência, naturalmente 
sempre precisaremos reconstruir a história de modo a ser uma ferramenta tanto no ensino dos conceitos da física quanto para se compreender também os processos de construção do conhecimento científico, no nível de ensino adequado. E se, pelas limitações de tempo e outros fatores, não podemos analisar profundamente a história tratada, então se precisa coragem, talvez, para fazer o que é possível. Ou seja, "se a exaustividade em considerar os fatos do passado consiste realmente num requisito fundamental para se ter uma "boa história", a "má história"é o que sempre restará para o ensino. Mas, então, quais histórias sobrariam como aceitáveis em educação científica?"(SILVA; LABURÚ, 2010, p. 79).

Naturalmente, ao professor interessado nessas questões é necessário um discernimento em relação às suas necessidades e capacidades, de modo a não incorrer em pseudo-histórias, mas também saber que sempre haverá um grau de inexatidão e viés epistemológico em suas narrativas. Por isso compactuamos com a sugestão de que os

professores tenham conhecimento filosófico para que, conscientemente, a partir da história 1 (que se baseia em reais eventos históricos), exponha uma reconstrução histórica constituída de uma história 2 (que engloba as proposições históricas) carregada pela postura filosófica propositadamente aplicada ao ensino (SILVA; LABURÚ, 2010, p. 80).

As reconstruções históricas realizadas com um objetivo didático podem permitir então que se encontre um equilíbrio entre uma análise exaustiva de elementos históricos não relevantes (talvez) ao aluno, e uma história descompromissada perniciosa à sua formação. Não queremos precipuamente formar historiadores e sociólogos da ciência, mas pensamos que a preocupação com os processos de construção do conhecimento científico é a forma mais imediata de promover um ensino sobre ciência, além de apenas seus resultados.

Alguns autores são consensuais em relação à necessidade de se superar uma visão essencialmente empirista da ciência (MOREIRA; OSTERMANN, 1993, SILVEIRA; OSTERMANN, 2002; SILVEIRA; PEDUZZI, 2006; PRAIA et al., 2007), o que sugere um ponto de partida para se estruturar atividades que visem uma caracterização da atividade científica mais consonante com os resultados das pesquisas na área. Ainda, em geral o interesse com as investigações em ensino de ciências focadas na natureza da ciência costumam se basear em duas hipóteses: a) o entendimento da natureza da ciência pelo professor influencia a imagem que os alunos constituem a respeito dela, e b) as crenças do professor sobre a natureza da ciência influencia significativamente nas suas decisões didáticas em sala (ACEVEDO et al., 2005, p. 3). "Contudo, por muito atrativas que possam parecer ambas as hipóteses, o certo é que ainda não estão suficientemente validadas pelas investigações realizadas"(ACEVEDO et al., 2005, p. 3).

Praia, Gil-Pérez e Vilches (2007) trazem algumas respostas aos apontamentos de Acevedo et al. (2005) e apontam que o estudante deve ser inclusive imerso em uma cultura científica, ultrapassando uma condição de simples ponto de vista em relação à natureza da ciência (2007, p. 146). Compactuamos também com a sugestão desses autores de que devemos proceder de modo a formar uma imagem 
da metodologia científica - longe de qualquer ideia de algoritmo com que freqüentemente se apresenta - na qual nada garante que se chegará a um bom resultado, mas que representa, sem dúvida, a melhor forma de orientar o tratamento de um problema científico (como atestam os impressionantes edifícios teóricos construídos) (PRAIA; GIL-PÉREZ; VILCHES, 2007, p. 149).

Em 2003, segundo Moreira (2003, p. 6), o conhecimento produzido sobre métodos, técnicas e estratégias de ensino em ciências encabeçava as pesquisas em ensino de ciências. Não obstante, pesquisas com a formação de professores de ciências estavam em uma posição bem inferior, ficando apenas à frente das pesquisas sobre o contexto da educação em ciências, novas tecnologias e avaliação. Em um levantamento um pouco mais recente, Cachapuz et al. (2008) aponta a filosofia da ciência como uma das maiores frequências entre as linhas de pesquisa em educação em ciência. Mas parece não haver muitos subsídios para o professor já em atuação e, infelizmente, parece que esta preocupação é majoritariamente acadêmica, havendo pouco reflexo na educação básica.

Fazendo alusão ao "professor-pesquisador", Moreira comenta sobre um "professorconsumidor", que efetivamente usaria o que aquele produziu. Este professor seria:

Um indivíduo que pelo menos soubesse, e tivesse o costume de ler criticamente artigos sobre educação em ciências escritos a partir de resultados de pesquisa. Que soubesse discriminar entre o que vem da investigação e o que é especulativo, opinativo, intuitivo (MOREIRA, 2003, p. 11).

Excetuando-se a idiossincrasia do professor, é lícito supor que sua formação tenha um papel central na constituição de uma prática com maior consonância com os resultados das pesquisas em ensino, mas também é sempre recomendável que procuremos otimizar a situação dos profissionais que já se encontram em atuação.

Grupos de professores em formação podem ser mais bem instruídos, para se evitar que visões inadequadas da atividade científica sejam levadas adiante, bem como grupos de professores já em atuação. Isto pode se dar por meios diferentes. Por exemplo, pode-se realizar uma apresentação inicial clara e direta das visões epistemológicas contemporâneas (MOREIRA; MASSONI; OSTERMANN, 2007), ou de um modo mais perscrutador, através de discussões baseadas em textos originais históricos e epistemológicos, para identificar as concepções iniciais dos alunos e para uma futura discussão epistemológica calcada nos preceitos contemporâneos (TEIXEIRA; EL-HANI; FREIRE Jr., 2001). De um modo ou de outro, é importante perceber cada vez mais a necessidade de se trazer ao professor em formação essas discussões epistemológicas, sem ignorar outras atividades, em outros espaços, que permitam ao professor em atuação também fazer parte nesse processo.

Uma das mais prementes necessidades de se trabalhar com a natureza da ciência junto aos professores, como citado anteriormente, é o fato de que sua visão a respeito da natureza da ciência influenciará, em maior ou menor grau, a visão que o aluno constituirá a respeito da atividade científica, conforme sugerem pesquisas realizadas nos EUA com esse fim (LEDERMAN, 1992; ABD-EL-KHALICK; LEDERMAN, 2000). Conforme aponta Lederman, 
"os fatores mais importantes que influenciam as visões dos estudantes sobre a natureza da ciência são aqueles relacionados às atividades instrucionais específicas implementadas no contexto de aula"(1992, p. 351). Disso resulta uma preocupação em relação à visão do professor em relação à atividade científica, sendo que um trabalho realizado por Chinelli e colaboradores mostrou que existem, convivendo nas escolas,

concepções epistemológicas distintas, muitas vezes assumidas por um mesmo professor. Esta situação conflitante produz práticas pedagógicas antagônicas, fragilizando o ensino de ciências em razão de incoerências que podem ser sentidas pelos estudantes (CHINELLI et al., 2010, p. 31).

Em um trabalho pioneiro realizado na década de 1980 sobre estereótipos sociais dominantes relativos à imagem de ciência, alguns autores já tinham concluído que o currículo oculto das escolas transmite uma imagem inadequada da ciência, tanto aos estudantes como aos professores (PORLÁN; RIVERO, 1998). As caraterísticas apontadas, dessa imagem inadequada da ciência, são: a) a verdade científica existe fora de nossas mentes; b) na explicação do professor se tende a dar a sensação de que ao final sempre há uma conclusão objetiva e verdadeira; c) os cientistas, segundo o currículo escolar, são pessoas especialmente inteligentes e, em certa medida, superiores às demais; d) as questões que a ciência ainda não resolveu têm solução, o que ocorre é que os cientistas ainda não as abordou; e) a ciência é cumulativa e segura.

Em um trabalho abrangente realizado por Fernández e colaboradores também foi constatado que diversos artigos sobre o ensino de ciências (e consequentemente diversos professores, que produziram aqueles) apresentam uma imagem inadequada da atividade científica. Estes autores usaram sete categorias de visões inadequadas (os autores usam "deformadas") em relação à ciência (FERNÁNDEZ et al., 2002, p. 483): visão empírico-indutivista e ateórica, que assume que o conhecimento científico começa com a observação supostamente neutra de dados e ignora o papel das teorias enquanto organizadoras do conhecimento e mesmo da experimentação; visão rígida (algorítmica, exata, infalível), que transmite a noção de que a ciência opera com um método científico único e bem delimitado; visão aproblemática e ahistórica, que ignora os problemas que levaram ao conhecimento científico e a história associada ao seu desenvolvimento; visão exclusivamente analítica, que foca apenas em elementos isolados do conhecimento, ignorando as grandes teorias organizadoras da ciência e a relação entre seus conhecimentos; visão cumulativa, de crescimento linear, que transmite a ideia de que a ciência cresce por meio do acúmulo de descobertas, ignorando, portanto, as rupturas e ressignificações ao longo da história; visão individualista e elitista, que adota uma imagem do cientista como um indivíduo superior aos demais e ignora as colaborações coletivas na ciência; e, por fim, visão socialmente descontextualizada, que vê a ciência como uma instituição fechada e ignora as influências sociais em seu desenvolvimento.

Essas categorias não se mostram totalmente independentes, apoiando-se mutuamente em muitos casos (FERNÁNDEZ et al., 2002). Disso, resulta que uma visão mais adequada da atividade científica residiria em uma oposição a essas categorias, e que os alunos não irão adquirir essa visão se os próprios professores não a possuem. 


\section{Alguns Resultados}

Ilustremos brevemente alguns exemplos do que anda sendo feito no ensino de ciências para levar essas discussões junto aos estudantes. Em um estudo exploratório realizado em uma escola pública (SILVA, 2010), houve uma implementação de questionários versando sobre aspectos da natureza da ciência com turmas ingressantes e turmas concluintes do Ensino Médio, com um total de 80 estudantes. Entre os resultados, temos ratificada a noção academicamente já consensual de que os alunos possuem visões inadequadas a respeito da atividade científica, e "que as concepções de ciências tanto do aluno ingressante como do concluinte [do Ensino Médio] pouco diferem entre si"(SILVA, 2010, p. 626). O que atesta a ineficiência das discussões realizadas ao longo do Ensino Médio, ao menos em relação aos modos de operar da ciência. Nesse sentido, a menos que se realizem esforços para se trabalhar adequadamente com tópicos acerca da natureza da ciência, é lícito supor que a imagem de ciência dos alunos continuará sendo aquela socialmente compartilhada, repleta de problemas. Como o autor do estudo comenta, a discrepância entre as visões de natureza da ciência tidas como adequadas pelos pesquisadores e as visões constituídas pelos estudantes "pode ser explicada pelo espaço enorme entre as discussões e as produções realizadas pelos pesquisadores da área e os professores de ciências do ensino fundamental e médio, que estão na outra ponta do iceberg"(SILVA, 2010, p. 676).

Um outro trabalho exploratório, realizado com estudantes de Ensino Médio de uma escola técnica (MARUYAMA; BRAGA; GUERRA, 2011), em um curso de Física Experimental, teve um propósito semelhante ao trabalho anteriormente citado, mas com 165 alunos ingressantes no curso. Uma das constatações foi em relação à diferenciação entre "teoria"e "lei", onde, para a maioria dos estudantes, essa estaria "baseada em algum tipo de comprovação. A experimentação seria o grande tribunal dessa diferenciação. [...] Esta diferença é determinada pela comprovação experimental"(MARUYAMA; BRAGA; GUERRA, 2011, p. 6). Ou seja, temos a noção de senso comum de que "teoria"é algo que não foi comprovado e "lei"é algo que foi. Assim como nós, os autores defendem que:

A identificação antecipada das visões deformadas da ciência (GIL-PÉREZ et al., 2001) podem gerar uma estimativa futura das dificuldades de apreensão do conteúdo de $\mathrm{NdC}$ [natureza da ciência] que os alunos possam apresentar fornecendo ao docente subsídios para a criação de um cenário propício à melhoria do ambiente de ensino (MARUYAMA; BRAGA; GUERRA, 2011, p. 6).

Como mencionamos, é licito supor que essas visões não serão significativamente alteradas junto aos alunos se os próprios professores não tiverem uma visão mais sofisticada em relação aos elementos mais consensuais a respeito da atividade científica. Contudo, possuir visões adequadas da natureza da ciência não resulta necessariamente em práticas mais efetivas para a promoção de uma melhor visão também por parte dos alunos (LEDERMAN, 1992, p. 351). É claro que é preciso sistematizar maneiras de se permitir que o aluno construa essa visão mais adequada, como os exemplos a seguir. 
A partir de uma parceria entre professores da escola pública e um grupo de especialistas em ensino de física, houve a estruturação de um curso de termodinâmica para o Ensino Médio que incluía textos históricos para a discussão sobre o desenvolvimento da ciência (NASCIMENTO; CARVALHO, 2007). Essa discussão junto aos alunos foi feita para que eles "pudessem compreender aspectos importantes sobre o conhecimento científico e, dessa maneira, construíssem uma visão mais realista sobre a natureza desse conhecimento"(NASCIMENTO; CARVALHO, 2007, p. 3). O curso incluía experiências de demonstrações investigativas, vídeos e softwares, e questões para discussões em grupo, com aulas filmadas. Os pesquisadores obtiveram "evidências de que o uso de textos históricos valoriza o ensino e a aprendizagem de aspectos [caracterizados] como componentes básicos da alfabetização científica"(NASCIMENTO e CARVALHO, 2007, p. 11).

Como proposta de trabalho com a natureza da ciência no Ensino Médio, Köhnlein e Peduzzi (2005) estruturaram e implementaram um módulo didático sobre a Teoria da Relatividade Restrita, com uma abordagem histórico-filosófica. Esse trabalho evidenciou que uma abordagem histórico-filosófica chama atenção do aluno, e que ao término do módulo houve uma modificação considerável em relação à superação de uma visão empírica-indutivista, constatada inicialmente. É oportuno citar que os próprios livros didáticos costumam não ajudar nesse sentido, ou seja, no geral eles também trazem uma visão de ciência que se aproxima mais do empirismo e do indutivismo (KÖHNLEIN; PEDUZZI, 2005, p. 63). Ao usar Kuhn como referencial epistemológico, os autores sugerem que "a interpretação históricofilosófica [...], utilizada no módulo didático, não é a única. O [trabalho desenvolvido] abre perspectivas para os que desejam elaborar novas estratégias para abordar esse tópico à luz das concepções de outros filósofos contemporâneos"(KÖHNLEIN; PEDUZZI, 2005, p. 64). Naturalmente compartilhamos da visão de que diferentes referenciais podem ser utilizados em propostas compromissadas com uma visão adequada da atividade científica.

Em um trabalho de 2010, a partir de uma unidade de ensino com a ótica, onde houve uma preocupação com a natureza da ciência, Silva e Martins chamaram atenção de que não existem metodologias infalíveis, e que ao fim de uma intervenção didática é possível que algumas concepções iniciais sejam retomadas pelos alunos. Mas no geral se percebeu que as atividades realizadas "permitiram uma reflexão e um melhor entendimento de questões relativas ao desenvolvimento da ciência"(SILVA; MARTINS, 2010, p. 90), e que "os alunos se tornaram mais participativos, principalmente os que se mostravam mais avessos às ciências"(SILVA; MARTINS, 2010, p. 90).

Uma tentativa corajosa de se comentar sobre a natureza do conhecimento científico nos anos iniciais do Ensino Fundamental foi organizada por Longhini e Mora (2009), que desenvolveram um estudo exploratório que consistia em trazer fotos de partes de objetos para as crianças, seguido de questionamentos a respeito do que era visto. Essa atividade traz a interessante sugestão de trazer elementos sobre a investigação científica junto a crianças, ao tratar a imaginação (hipóteses!) como ferramenta para se descobrir mais sobre algo. Consideramos relevante o esclarecimento seguinte:

Logicamente, seria ingênuo acreditar que [a criança] pode elucidar os diversos meandros do processo de produção do conhecimento científico, que vão muito além de um ensaio como o que propomos. [...] O que pretendemos é 
oferecer alguns subsídios para início de um processo que não se esgota nos primeiros anos da escolarização, mas que deveria perpassar todas as etapas da Educação Básica (LONGHINI; MORA, 2009, p. 6)

Em um trabalho minucioso realizado por Forato (2009), um conjunto de estratégias para se ensinar a natureza da ciência no Ensino Médio foi implementado em uma unidade de ensino sobre a história da luz. Nesse trabalho ficou evidente que "explorar a utilização da história da ciência no ensino médio mostrou-se um recurso pedagógico favorável e instigador para ensinar sobre a natureza da ciência"(FORATO, 2009, p. 183). Apesar das recomendações historiográficas em relação ao tratamento da história da ciência de modo a evitar as distorções já comentadas, por exemplo, Forato ratifica que "não é possível tratar um recorte histórico e discuti-lo em seus detalhes como recomendável em trabalhos especializados"(FORATO, 2009, p. 191). No final, sempre precisaremos de um discernimento adequado para escolher e gerenciar os caminhos didáticos escolhidos, cientes das consequências inevitáveis de nossas escolhas, positivas e negativas. Mas parece claro que:

[...] a necessidade de um ensino explícito da $\mathrm{NdC}$ [natureza da ciência] no currículo de ciências suscita um acordo cada vez mais amplo, tanto entre os pesquisadores de didática da ciência quanto nos modelos dos currículos renovados da educação científica (VÁSQUEZ-ALONSO et. al., 2008, p. 34).

Diante desse acordo crescente, ao nosso ver é urgente que cada vez mais iniciativas voltadas à educação básica sejam engendradas, para que a falta de propostas didáticas compromissadas com uma imagem mais adequada da atividade científica se torne um problema a menos entre tantos ainda a resolver.

\section{Algumas sugestões}

Muitas propostas didáticas, não temos dúvidas de que verdadeiramente compromissadas em "prender a atenção do aluno", fundamentam-se em uma visão empírico-indutivista da atividade científica. Como práticas para se trabalhar determinados conceitos, podem realmente ter sua valia. Também não temos dúvidas de que práticas experimentais, por exemplo, são valiosas para levar o aluno a uma posição mais ativa perante o aprendizado (o que por si só já é algo valioso para se aprender melhor), ao mesmo tempo em que também costuma despertar seu interesse pelo assunto.

As aulas experimentais têm uma grande importância, e pensamos que nunca podemos subvalorizar seu papel no ensino. Os alunos claramente costumam se entreter positivamente com as ilustrações, na "prática", dos exemplos estudados de dinâmica e estática, termologia, ótica, eletromagnetismo, etc. Essas atividades também são muito importantes como metodologia ativa, para promover as diferenciações progressivas e reconciliações integradoras de uma aprendizagem significativa (MOREIRA, 2012).

Mas quando se trata de formar uma imagem mais abrangente da atividade científica, parece claro que apenas isso não basta. O aluno precisa presenciar, sempre que possível, 
os fenômenos físicos básicos que ele estuda, juntamente com atividades e exercícios de fixação do livro didático, mas se não houver uma sistematização no sentido de levá-lo a perceber o papel da experimentação na pesquisa científica, teremos falhado em ensinar ciência. Teremos, no máximo, ensinado alguns de seus resultados, mas provavelmente o teremos feito com alguns "ruídos", proferindo algo como, por exemplo, "Galileu chegou nessa lei de queda dos corpos usando o método científico, observando de forma neutra os fenômenos e chegando numa lei matemática a partir dos dados obtidos"(apenas para ilustrar uma visão empirista ingênua de ciência).

Ouvimos quase onipresentemente o termo "método científico"no contexto do ensino das ciências naturais, em práticas que levam os alunos a acreditarem que o cientista, normalmente um sujeito mais aguçado do que as "pessoas normais", segue um conjunto rígido e bem definido de diretrizes, fazendo descobertas diretamente a partir dos dados brutos, em função deste método. Mas

esta concepção de método científico, bastante comum, dentro e fora da escola, é epistemologicamente equivocada, isto é, não é assim que se produz o conhecimento científico e, em consequência, didaticamente errada, quer dizer, não se deve ensinar ciência dessa maneira (MOREIRA; OSTERMANN, 1993, p. 108).

Então como devemos ensinar ciência? Ora, estaríamos indo do contexto educacional ao contexto impositivo dogmático se tivéssemos uma resposta a essa pergunta, no singular. Diante do exposto, o que podemos apontar são sugestões (ainda que devidamente embasadas) para práticas mais potencialmente significativas em relação ao que pode ficar com o aluno, ao final. Naturalmente, uma oposição consciente às visões distorcidas é algo que pode otimizar nossas práticas. Se ter concepções mais adequadas da atividade científica não nos garante engendrar situações didáticas mais eficazes, não as ter só pode piorar o quadro. Do mesmo modo que saber física é condição necessária e insuficiente para se ensinar física, sugerimos que conduzir práticas mais conscientes em relação aos elementos da natureza da ciência é condição necessária e insuficiente para se ensinar como a ciência funciona. Mas é um começo indispensável, sob pena de sermos coniventes com uma educação que pode levar o aluno a aprender de modo significativo uma visão totalmente equivocada da atividade científica. Sim, não nos esqueçamos que uma aprendizagem significativa não é sinônimo de uma aprendizagem de conceitos corretos (ou mais aceitos cientificamente). "As conhecidas concepções alternativas [...] geralmente são aprendizagens significativas (e, por isso, tão resistentes à mudança conceitual)"(MOREIRA, 2012, p. 7).

Pensamos que conduzir práticas mais conscientes em relação à natureza da ciência é insuficiente no sentido de que a meta-aula, na cabeça do professor, de modo algum pode ser confundida com o que ficará efetivamente com o aluno, ao final. Assim, se desejamos fazer com que ele se aproprie, de fato, das questões relativas à natureza da ciência, uma apresentação mais explícita nesse sentido deve ser observada. Por mais limitada que seja qualquer aproximação epistemológica pretendida, se deixarmos que os alunos "montem na cabeça"os elementos esparsos no discurso do professor, estaremos também "lavando as 
mãos"em relação ao nosso papel como professores. Pensamos que não seria diferente de ensinar aos alunos alguns conceitos esparsos de eletricidade e esperar que eles montassem um quadro consistente do eletromagnetismo. Então é importante que pensemos em práticas que ataquem frontalmente as questões epistemológicas pretendidas, por meio de toda a gama de possibilidades metodológicas.

Poder-se-ia contra-argumentar em relação a deixar os alunos montarem sua própria visão a respeito da atividade científica mencionando que é exatamente isso o que ocorrerá, de um jeito ou de outro. Concordamos, naturalmente. Nosso ponto é que, se já é desafiador conseguirmos ensinar uma imagem adequada da atividade científica com abordagens frontais da epistemologia (ARTHURY; TERRAZZAN, 2018), conduzir práticas esparsamente conscientes a esse respeito não propiciará um contexto mais profícuo.

Entrementes, é importante atentar para a possibilidade de se ir perigosamente ao extremo oposto, quando pretendemos relativizar a posição da ciência enquanto detentora de métodos infalíveis e verdades absolutas. Enfatizamos que isso exige atenção por parte do professor de ciências (ARTHURY; SILVA, 2020). Uma complexificação inadequada da atividade científica no contexto do ensino, ainda que bem-intencionada, pode levar o aluno por um caminho tão equivocado quanto o do empirismo e indutivismo (ALLCHIN, 2011; MARTINS, 2015). Isso pode ser desastroso à sua formação e mesmo para sua vida em sociedade, uma vez que estará mais suscetível às pseudociências e teorias conspiratórias baseadas em patente ignorância que, no melhor dos casos, apenas desinforma (vide os "terraplanistas") e, no pior, literalmente pode levar sua vida a risco (vide o movimento antivacina), passando por todo o espectro de engodos charlatãos que, no mínimo, tiram proveito de sua credulidade ingênua

Os trabalhos citados anteriormente, e nossas discussões ao longo da apresentação dos mesmos, indicam alguns caminhos a seguir, sempre lembrando que, em última instância, qualquer prática é fruto da criatividade (e competência) do professor. Conhecemos caminhos mais profícuos que outros, e naturalmente um conhecimento adequado das pesquisas em ensino pode ajudar nas nossas escolhas.

\section{Considerações Finais}

Para além de se pretender ensinar visões mais adequadas da atividade cientifica, lembremos que um ensino preocupado com as questões históricas e epistemológicas pode ser um grande aliado para se ultrapassar o imenso vazio de significados de uma educação memorística de pouca ou nenhuma relevância ao aluno, uma educação que costumeiramente resume a física a um conjunto de ferramentas para se fazer avaliações. Ou, como perspicazmente descreveu um aluno, "uma marcha forçada através de um país desconhecido sem tempo para se olhar para os lados"(MATTHEWS, 2000, p. 289).

A ciência na educação escolar, claro, tem (ou deveria ter) propósitos muito mais abrangentes. A ciência também é pragmatismo em ação, mas é verdadeiramente uma pena que alguns professores tenham conseguido mostrar apenas isso. A aventura da ciência, da descoberta da realidade, "é a maior aventura jamais iniciada pela mente humana"(FEYNMAN et al., 1965, p. 21-19), apenas para muito bem representar o espírito científico. Não vemos como mostrar isso ao aluno sem percorrermos o caminho da evolução da ciência, seus 
problemas, seus sucessos, juntamente com todas as vicissitudes dos cientistas ao longo dos tempos. Poucos momentos são tão didaticamente valiosos quanto o interesse genuíno que os alunos costumam demonstrar ao se conversar sobre ciência, de fato, além de seus resultados. Conforme a provocação de Feynman, no mesmo trecho citado anteriormente, "as forças da instrução são de pouquíssima eficácia exceto naquelas felizes circunstancias em que são praticamente supérfluas". Qual a desculpa do dia para não prestarmos atenção a isso?

\section{REFERÊNCIAS}

ABD-EL-KHALICK, F.; LEDERMAN, N. G. The Influence of History of Science Courses on Students' Views of Nature of Science. Journal of Research in Science Teaching, v. 37, n. 10, p. 1057-1095, 2000.

ACEVEDO, J. A.; VÁZQUEZ, A.; PAIXÃO, M.; ACEVEDO, P.; OLIVA, J. M.; MANASSERO, M. A. Mitos da didática das ciências acerca dos motivos para incluir a natureza da ciência no ensino das ciências. Ciência \& Educação, v. 11, n. 1, p. 1-15, 2005.

ALLCHIN, D. Evaluating knowledge of the nature of (whole) science. Science \& Education, v. 95, n. 3, p. 518-542, 2011.

ALLCHIN, D. Pseudohistory and Pseudoscience. Science \& Education, v. 13, p. 179-195, 2004.

ARTHURY, L. H. M.; TERRAZZAN, E. A. A Natureza da Ciência na escola por meio de um material didático sobre a Gravitação. Revista Brasileira de Ensino de Física, v. 40, n. 3, p. 3403-1 - 3403-21, 2018.

ARTHURY, L. H. M.; SILVA, J. O. G. Em Prol do Realismo Científico no Ensino. Ciência \& Educação, v. 26, n. 1, p. 01-14, 2020.

CACHAPUZ, A.; PAIXÃO, F.; LOPES, J. B.; GUERRA, C. Do Estado da Arte da Pesquisa em Educação em Ciências: Linhas de Pesquisa e o Caso "Ciência-Tecnologia-Sociedade". Alexandria, v.1, n.1, p. 27-49, mar.2008.

CHINELLI, M. V.; FERREIRA, M. V. S.; AGUIAR, L. E. V. Epistemologia em sala de aula: a Natureza da ciência e da atividade científica na prática profissional de professores de ciências. Ciência \& Educação, v. 16, n. 1, p. 17-35, 2010.

FERNÁNDEZ, I.; PÉREZ ,D. G.; CARRASCOSA, J.; CACHAPUZ, A.; PRAIA, J. Visiones deformadas de la ciencia transmitidas por la enseñanza. Enseñanza de las Ciencias, v. 20, n. 3, p. 477-488, 2002.

FEYNMAN, R. P.; LEIGHTON, R. B.; SANDS, M. The Feynman Lectures on Physics. Vol. III. California: Addison-Wesley, 1965. 
FORATO, Thaís C. M. A Natureza da ciência como saber escolar: um estudo de caso a partir da história da luz. 2009. 204 f. Tese (Doutorado - Programa de Pós-Graduação em Educação). Faculdade de Educação da Universidade de São Paulo, Universidade de São Paulo, São Paulo, 2009.

FREIRE JR., O. A relevância da Filosofia e da História das Ciências para a formação dos professores de ciências. In: Waldomiro José da Silva Filho. (Org.). Epistemologia e Ensino de Ciências. Salvador: Arcadia, p. 13-30, 2002.

GAGLIARDI, R. Cómo utilizar la historia de las ciencias en la enseñanza de las ciencias. Enseñanza de las Ciencias, v. 6, n. 3, p. 291-296, 1988.

PÉREZ, D. G. et. al. Para uma imagem não deformada do trabalho científico. Ciência $\mathcal{E}$ Educação, v. 7, n.2, p. 125-153, 2001.

HOLTON, G. A imaginação científica. Rio de Janeiro: Zahar, 1979.

KÖHNLEIN, J. F. K.; PEDUZZI, L. O. Q. Uma discussão sobre a Natureza da ciência no ensino médio: um exemplo com a teoria da relatividade restrita. Caderno Brasileiro de Ensino de Física, v. 22, n. 1, p. 36-70, abr. 2005.

KUHN, T. S. A estrutura das revoluções científicas. São Paulo: Perspectiva, 1970.

KUHN, T. S. A função do dogma na investigação científica. In: A Crítica da Ciência. Rio de Janeiro: Zahar, 1979.

LEDERMAN, N. G. Nature of Science: Past, present, and future. In: ABELL, S.; LEDERMAN, N. G. Handbook of research in Science Education. New York: Routledge, 2007.

LEDERMAN, N. G. Students' and teachers' conceptions of the nature of science: a review of the research. Journal of Research in Science Teaching, v. 29, n. 4, p. 331-359, 1992.

LONGHINI, M. D.; MORA, I. M. A natureza do conhecimento científico nas aulas de ciências nos anos iniciais do ensino fundamental. Atas do VII Encontro Nacional de Pesquisa em Educação em Ciências - VII ENPEC Florianópolis, SC - 8 a 13 de novembro de 2009. Disponível em: < http:// posgrad.fae.ufmg.br/posgrad/viienpec/pdfs/245.pdf>. Acesso em: 8 ago. 2015.

MARTINS, A. F. Natureza da ciência no ensino de ciências: uma proposta baseada em "temas"e "questões". Caderno Brasileiro de Ensino de Física, v. 32, n. 3, p. 703-737, dez. 2015.

MARTINS, R. de A. Sobre o papel da história da ciência no ensino. Boletim da Sociedade Brasileira de História da Ciência, n. 9, p. 3-5, 1990.

MARUYAMA, U., BRAGA, M., GUERRA, A. Leis $\mathcal{E}$ teorias: identificando aspectos so- 
bre visões de Natureza da ciência em estudantes do ensino médio num curso de física experimental. Atas do VIII Encontro Nacional de Pesquisa em Educação em Ciências - VIII ENPEC Campinas, SP - 5 a 9 de dezembro de 2011. Disponível em: < http:// www.nutes.ufrj.br/abrapec/viiienpec/resumos/R0257-1.pdf >. Acesso em: 20 jul. 2015.

MATTHEWS, M. R. Construtivismo e o ensino de ciências: uma avaliação. Caderno Brasileiro de Ensino de Física, v. 17, n.3, p. 270-294, dez. 2000.

MATTHEWS, M. R. História, filosofia e ensino de ciências: a tendência atual de reaproximação. Caderno Brasileiro de Ensino de Física, v. 12, n. 3, p. 164-214, dez. 1995.

MOREIRA, M. A. Al final, qué es aprendizaje significativo? Revista Qurriculum, v. 25, p. 29-56, 2012.

MOREIRA, M. A. Pesquisa básica em educação em ciências: uma visão pessoal. Disponível em: http://www.if.ufrgs.br/ moreira/Pesquisa.pdf. Acesso em: 20 fev. 2009.

MOREIRA, M. A.; MASSONI, N. T.; OSTERMANN, F. História e epistemologia da física na licenciatura em física: uma disciplina que busca mudar concepções dos alunos sobre a Natureza da ciência. Revista Brasileira de Ensino de Física, v. 29, n. 1, p. 127-134, 2007.

MOREIRA, M. A.; OSTERMANN, F. Sobre o ensino do método científico. Caderno Brasileiro de Ensino de Física, v. 10, n. 2, p.108-117, ago. 1993.

NASCIMENTO, V. B.; CARVALHO, A. M. P. A natureza do conhecimento científico e o ensino de ciências. Atas do VI Encontro Nacional de Pesquisa em Educação em Ciências - VI ENPEC Florianópolis, SC - 26 de novembro a 1 de dezembro de 2007. Disponível em: http:// axpfep1.if.usp.br/ profis/arquivos/vienpec/CR2/p452.pdf. Acesso em: 12 ago. 2015.

OLIVEIRA, B. J.; FREIRE JR., O. Uma conversa com Gerald Holton. Caderno Brasileiro de Ensino de Física, v. 23, n. 3, p. 315-328, dez. 2006.

PEDUZZI, L. O. Q.; ZYLBERSZTAJN, A.; MOREIRA, M. A. As concepções espontâneas, a resolução de problemas e a história da ciência numa seqüência de conteúdos em mecânica: o referencial teórico e a receptividade de estudantes universitários à abordagem histórica da relação força e movimento. Revista Brasileira de Ensino de Física, v. 14, n. 4, p. 239-246, 1992.

PENA, Fábio L. A. Sobre a presença do Projeto Harvard no sistema educacional brasileiro. Revista Brasileira de Ensino de Física, v. 34, n. 1, p. 1701-1 - 1701-4, 2012.

PORLÁN, R.; RIVERO, A. El conocimiento de los professores. Sevilla: Díada Editorial S. L., 1998.

PRAIA, J.; GIL-PÉREZ, D.; VILCHES, A. O papel da Natureza da ciência na educação para a cidadania. Ciência \& Educação, v. 13, n. 2, p. 141-156, 2007. 
SÁNCHEZ RON , J. M. Usos y abusos de la historia de la física em la enseñanza. Enseñanza de las Ciencias, v. 6, n. 2, p. 179-188, 1988.

SILVA, B. V. C. A Natureza da ciência pelos alunos do ensino médio: um estudo exploratório. Latin-American Journal of Physics Education, v. 4, n. 3, p. 670-677, 2010.

SILVA, B. V. C.; MARTINS, A. F. P. A natureza da luz e o ensino da óptica: uma experiência didática envolvendo o uso da história e da filosofia da ciência no ensino médio. Experiências em Ensino de Ciências, v. 5, n. 2, p. 71-91, 2010.

SILVA, O. H. M.; LABURÚ, C. E. Inserção de componentes históricos e filosóficos em disciplinas das ciências naturais no ensino médio: reflexões a partir das controvérsias historiográficas entre Kuhn e Lakatos. Revista Electrónica de Investigación en Educación en Ciencias, v. 5, n. 2, p. 69-82, dez. 2010.

SILVEIRA, F. L.; OSTERMANN, F. A insustentabilidade da proposta indutivista de "descobrir a lei a partir de resultados experimentais". Caderno Brasileiro de Ensino de Física, v. 19, n. especial, p. 7-27, jun. 2002.

SILVEIRA, F. L.; PEDUZZI, L. O. Q. Três episódios de descoberta científica: da caricatura empirista a uma outra história. Caderno Brasileiro de Ensino de Física, v. 23, n. 1, p. 26-52, abr. 2006.

SOLBES, J.; TRAVER, M. Resultados obtenidos introduciendo historia de la ciencia en las classes de física y química: mejora de la imagen de la ciencia y desarrolo de actidudes positivas. Enseñanza de las Ciencias, v. 19, n. 1, p. 151-162, 2001.

TEIXEIRA, E. S.; EL-HANI, C. N.; FREIRE JR., O. Concepções de estudantes de física sobre a Natureza da ciência e sua transformação por uma abordagem contextual do ensino de ciências. Revista da ABRAPEC, v. 1, n. 3., p. 111-125, 2001.

VÁSQUEZ-ALONSO, A.; MANASSERO-MAS, M. A.; ACEVEDO-DÍAZ, J. A.; ACEVEDOROMERO, P. Consensos sobre a Natureza da ciência: A Ciência e a Tecnologia na Sociedade. Química Nova na Escola, n. 27, p. 34-50, 2008.

VILLANI, A. Filosofia da ciência e ensino de ciência: uma analogia. Ciência e Educação, v. 7, n. 2, p. 169-181, 2001.

ZYLBERSZTAJN, A. Galileu - um cientista e várias versões. Caderno Brasileiro de Ensino de Física, n. 5 (número especial), p. 36-48, jun. 1988. 